\title{
Päivi Mehtonen
}

\section{Vertailevaa intohimoa Taiwanissa}

\section{Obsession in Context. The Fourth East Asian Conference on Comparati- ve Literature. 10.3.2012. Soochow University, Taipei, Taiwan.}

Neljännessä Itä-Aasian vertailevan kirjallisuudentutkimuksen konferenssissa maaliskuussa 2012 keskityttiin intohimoihin ja pakkomielteisiin kirjallisuuden, mystiikan ja filosofian välimaastoissa. Järjestäjinä toimivat Taiwanin Comparative Literature Association ja Taipein Soochow-yliopiston Englannin laitos.

Osallistujat saivat tervetuliaislahjaksi edellisen konferenssin julkaisun, jonka teema oli The Wounded Body in Literature (toim. Jonathan Klassen, Yauling Hsieh ja Joel Janicki, Soochow University 2012). Siinä käsitellyt yksilön ja kulttuurin traumat sekä kielen haavoittavuus/haavoittuvuus saivat nyt jatkoa esitelmistä, joissa luovuuden, rationalismin ja tunteiden konflikteja tutkivat osallistujat Taiwanin lisäksi EteläKoreasta, Filippiineiltä, Havaijilta, Hong Kongista, Iranista, Iso-Britanniasta, Kuwaitista, Suomesta ja Yhdysvalloista.

Perinteinen vertaileva tutkimus näkyi yllättävän vahvana, sekä yksittäisten teosten että laajemmin kulttuurienvälisen vertailevan navigoinnin merkityksessä. Työryhmien esitelmissä kohtasivat toisensa vaikkapa Julia Alvarez ja Katherine Min; tai Charles Palahniuk ja Brett Easton Ellis; tai Edgar Allan Poen kirjallinen intohimo hampaisiin ja D. H. Lawrencen saariin, 'islomania'.

Perinteistä vaikutelmaa vahvistivat myös kaksi pääesitelmää, jotka sekä kritisoivat että puolustivat vertailevaa otetta laajassa mielessä. Wai-Yee Li (Harvard University) poimi kiinalaisen kirjallisuuden pitkästä historiasta esimerkkejä ja anekdootteja erilaisista pakkomielteistä, kehitellen genealogiaa, joka paljastaa yhtäläisyyksiä ja eroja muihin kulttuureihin. Tunteiden historiaa Li tutki jo teoksessaan Enchantment and Disenchantment: Love and Illusion in Chinese Literature (Princeton University Press 1993).

Toisen pääesitelmän piti "Taiwanin helmenä” esitelty Shu-Mei Shih (University of California, LA), joka niin ikään edusti suurten kielialueiden komparatismia. Esitelmässä "The Obsession to Compare" (mandariini)kiina, englanti ja arabia esitettiin haasteina ja kielialueina, joiden välistä vertailevaa tutkimusta ja käännöstoimintaa tulisi lisätä. Shih'n viimeisimpiin tutkimuksiin ja toimituksiin kuuluvat Creolization of Theory (Duke University Press 2011) sekä Sinophone Studies: A Critical Reader (Columbia University Press, tulossa). Shih'n esitelmän yhteydessä reuna-eurooppalaista, Taiwania paljon pienemmän kulttuurin edustajaa kylmäsi se yleistävä merkitys, jonka sana 'eurooppa- 
laisuus' sai Shih'n esitelmän suurissa linjoissa. Yhdysvaltalais-taiwanilaisesta vinkkelistä 'eurosentrisyys' kävi edelleen syntipukista niin vertailevan tutkimuksen sisältöjen kuin menetelmien hegemonisuutta vastustaessa. Jonkinlaista käännettyä orientalismia.

Suurten linjojen lomassa pieni konferenssi tarjosi tilaisuuden tutustua paikalliseen kulttuuriin ja tutkimukseen. Taiwanilaisuus on kirjallisuuden näkökulmasta mielenkiintoinen pähkinä, eritoten saaren kieliä hallitsemattomalle ulkopuoliselle mutta myös ajankohtaisena debattina paikan päällä.

Asiaa kysyessä sai taiwanilaiskollegoilta yhtä monta vastausta kuin oli vastaajaa; esimerkiksi tiedustelut kätevästä "Taiwanin kirjallisuushistoriasta" - poliittinen tabu vuoteen 1987 - osoittautuivat ehtymättömäksi keskustelunaiheeksi. (Hyvä paikka aloittaa on vaikkapa Transformation! Innovation? Perspectives on Taiwan Culture, toim. Christina Neder ja Ines Susanne Schilling, Harrassowitz Verlag, Studia Formosiana 2003). Kyse on kielten ja traditioiden moninaisuudesta sekä Kiinan poliittisten käänteiden ja muuttoliikkeiden kerroksista.

Yksi kerros on tiivistä kirjallista ja kielellistä yhteyttä manner-Kiinaan ja sen monituhatvuotiseen traditioon. Esimerkiksi konferenssiin osallistunut taipeilainen kirjallisuustieteilijä An-Chi Wang sanoo kysyttäessä tutkijanidentiteetikseen "kiinalainen Taiwanista"; hänen teoksensa Gulliver's Travels and Ching-hua yuan Revisited. A Menippean Approach (Peter Lang 1995) on vertaileva tutkimus, joka myös asettaa menetelmänsä lasin alle (luku "Imposing Western theories on a Chinese Text?"). Toinen kollega kertoo olevansa "taiwanilainen". Tällöin kiinalaisuuden rinnalle tai ohitse nousee japanilaisen kulttuurin vaikutus ja arvostus tai Taiwanin alkuperäiskulttuurien ja (myös kirjoittamattomien) kielten historia ja elvytyspyrkimykset. Myös Taiwanin kiinalaisuus on kaikkea muuta kuin kielellisesti ja historiallisesti yhtenäinen kulttuuri. Taiwanin kirjallisuuden määrittely-yritys kielen perusteella on siis mahdoton tehtävä (tosin joku yhden kielen liikkeen edustaja olisi tästäkin eri mieltä).

Nämä keskustelut olivat pienen konferenssin parasta oheisantia. Esitelmissä Taiwanin kirjallisuus ei ollut vahvasti edustettuna, mikä oli luonnollista järjestäviä tahoja ajatellen.

Erityismaininnan ansaitsevat konferenssijärjestelyt. Sama ystävällinen täsmällisyys ja ripeys, joilla käytännön asiat sujuvat yhdessä maailman tiheimmin asutuista alueista, toimi loistavasti myös konferenssissa. Istunnoissa ei suvaittu ylipitkiä puheita, vaan jo ohjelmassa esiteltiin yhteiset säännöt. Jokaisen esitelmän 18. minuutin kohdalla (avustajan) kello soi yhden kerran, 20. minuutin kohdalla kahdesti, ja silloin tuli lopettaa "promptly". Absurdi ajatuksena mutta tätä voi ehdottomasti suositella, avustajien hymyjen ja kellonheilutusten maustamana. Konferenssi vailla loppumattomia tarinoita ja narsistista tajunnanvirtaa. 